\title{
Hybrid Electrical Air-Cushion Tracked Vehicle for Swamp Peat in Malaysia
}

\author{
Ataur Rahman ${ }^{*}, 1$, A.K.M. Mohiuddin ${ }^{1}$, Altab Hossain ${ }^{1}$ and Azmi Yahya ${ }^{2}$ \\ ${ }^{I}$ Department of Mechanical Engineering, Faculty of Engineering, International Islamic University Malaysia (IIUM), \\ 53100 Kuala Lumpur, Malaysia \\ ${ }^{2}$ Faculty of Engineering, Universiti Putra Malasia, 43400 Serdang, Selangor D.E Malaysia
}

\begin{abstract}
The aim of this paper is to present a hybrid electrical air-cushion tracked vehicle (HETAV) for the operation on swamp peat. Mathematical models are incorporated with accounting kinematics and dynamics behaviors of the vehicle. Sinkage of the HETAV is sensed by an ultrasonic displacement (UD) sensor, in order to operate the air-cushion system. The air-cushion of HETAV is protected with a novel-design auto-adjusting supporting (AAS) system. A propeller is equipped with the vehicle to develop additional thrust for overcoming the dragging motion resistance of the air-cushion system . The performance of the HETAV is defined by traction and motion resistance. The mean value of traction for the swamp terrain with propeller over without propeller increases $10.21 \%$ and $6.47 \%$ for the vehicle weight of $1.02 \mathrm{kN}$ and $2.04 \mathrm{kN}$, respectively. Similarly, it was found that the mean values of vehicle's motion resistance decrease $12.63 \%$ and $25.81 \%$ for the vehicle weight of $2.45 \mathrm{kN}$ and $3.43 \mathrm{kN}$, respectively.
\end{abstract}

Keywords: Hybrid vehicle, air-cushion, auto-adjusting-supporting system, UD sensor, propeller.

\section{INTRODUCTION}

The transportation operation of palm oil fresh fruit bunches (FFB) over the swamp peat terrain is considered as the biggest issue of Malaysia. Different types of University's research institute, government organization, and private companies were introduced different types of vehicles for solving the transportation problems on moderate peat terrain Ref. [1-4]. But still no one offered any vehicle on low bearing capacity swamp peat terrain. The bearing capacity in this study is defined as maximum load that a material (soil) can support before failing; and swamp is defined as a tract of wet or water-covered ground overgrown with trees and shrubs.

The main objective of the study is to design and develop the vehicle for justifying the concept to introduce a full-scale vehicle for the transportation operation of agricultural and industrial goods on the low bearing capacity swamp peat terrain in Malaysia. The propulsion system of the vehicle is comprised of track and air-cushion system. The track mechanism is used as the driving system to overcome the rolling motion resistance and the air cushion system is used to increase the floatation capacity of the vehicle. The driving force is provided to each of the track by an individual DC motor. The air-cushion system of this vehicle was designed in such a way that it would not slid on the terrain all the while with the vehicle movement. It only touches the ground and supports the partial load of the vehicle once the vehicle

*Address correspondence to this author at the Department of Mechanical Engineering, Faculty of Engineering, International Islamic University Malaysia (IIUM), 53100 Kuala Lumpur, Malaysia; Tel: +6-03-6196-4544; E-mail: arat@iiu.edu.my sinkage was closed to $50 \mathrm{~mm}$ or more. As the air is compressible fluid, so during the vehicle testing it was found that by increasing the vehicle sinkage the air-cushion supporting system was not sink. But, it slides over the ground once it touches the ground and supports the vehicle. The additional thrust (or tractive effort) is provided to the vehicle by using two propellers for overcoming the drag resistance of the air-cushion system. As the terrain is unprepared and different types of decomposed materials are on the terrain, the air-cushion was protected by a novel design protecting system. It can adjust on the terrain automatically when the vehicle traverse over the root and any other obstacles by absorbing its longitudinal displacement with two horizontally attached shock absorbers and vertical displacement with four vertically attached springs. The air-cushion system makes the vehicle ground contact pressure $5 \mathrm{kN} / \mathrm{m}^{2}$. The power transmission system of the vehicle is shown in Fig. (1). The magnetic pick-up sensor is used in this study to measure the vehicle theoretical speed.

\section{MATHEMATICAL MODEL}

Mathematical model is formulated with understanding the terrain nature and analyzing the mechanics of trackterrain interaction and the interaction of air-cushion supporting system-terrain. The vehicle is designed mainly for the operation on the swamp peat bearing capacity of 5 $\mathrm{kN} / \mathrm{m}^{2}$. So, the vehicle has chanced to sink even though its operating load is estimated, based on the bearing capacity of the terrain. The tractive effort and motion resistance of the vehicle are formulated in this study, based on two sinkage conditions: (i) sinkage, $0 \leq z \leq 5 \mathrm{~cm}$ when the vehicle is considered to operate on the moderate peat terrain, and (ii) sinkage, $z \geq 5 \mathrm{~cm}$ when the vehicle is considered to operate 


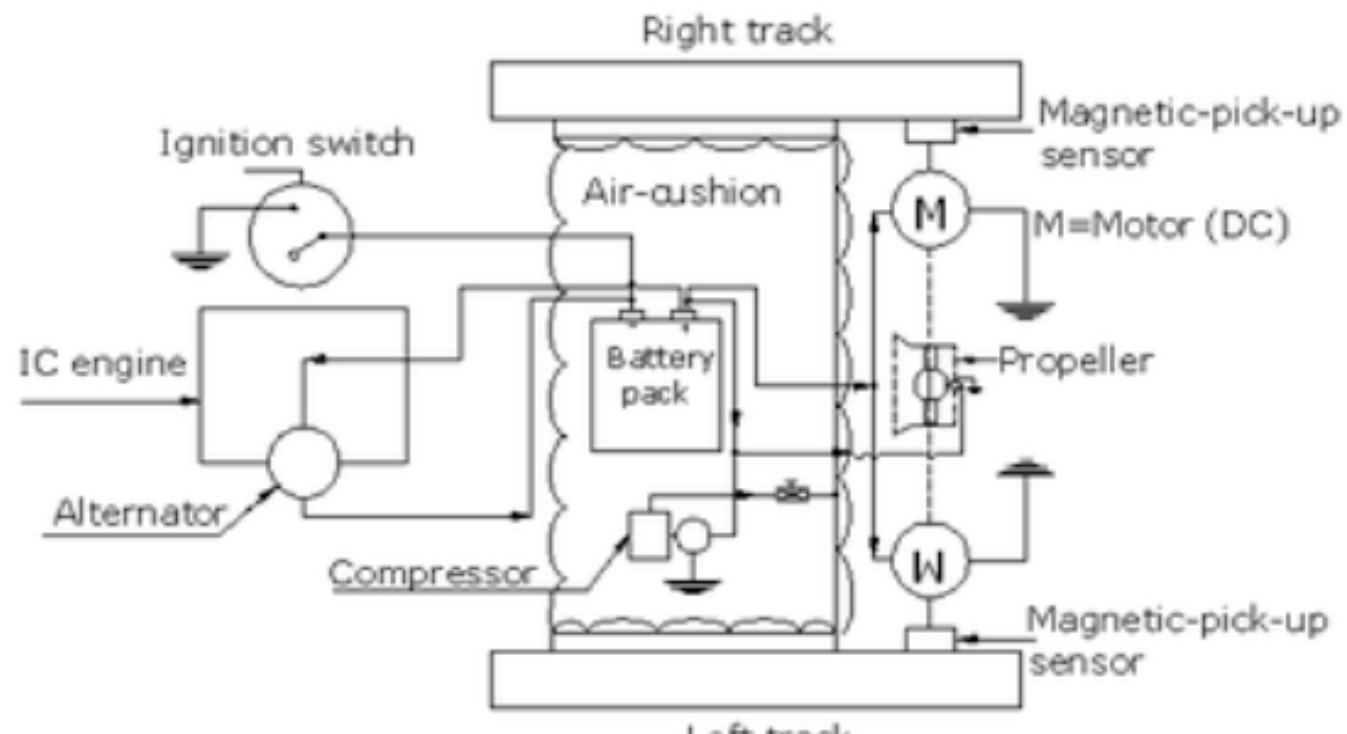

Left track

Fig. (1). Vehicle power transmission system.

on swamp peat. Assumptions are made in order to establish the mathematical models: (i) the pressure distribution in the track-terrain interface is assumed to be uniform by locating the vehicle C.G at the mid point of the track system, and (ii) critical sinkage of the vehicle is considered to be $120 \mathrm{~mm}$ based on the study of author ref. [5].

Consider a segmented rubber track vehicle of total weight $\mathrm{W}$, track size including track ground contact length $L$, width $B$, pitch $T_{p}$, and grouser height $H$, radius of the rear sprocket $R_{r s}$, and radius of the road-wheels $R_{r}$, that is traversing under traction on a swamp peat terrain at a constant speed of $v_{t}$ as soon as applying the driving torque $Q$ at the rear sprocket. The pressure distribution in the trackterrain interface is assumed to be uniform by locating the vehicle C.G at the mid point of the track system. The pressure at main straight part $P$, and rear sprocket $P_{r s}$, and the sinkage of the vehicle $z_{r w}$ and the sinkage of the rear sprocket $z_{r s}$ are revealed same as C.G of the vehicle is located at the middle of the track system, shown in Fig. (2).

\section{Traction}

The traction equations of the vehicle are developed, mainly based on the vehicle tracked-terrain and tracked-

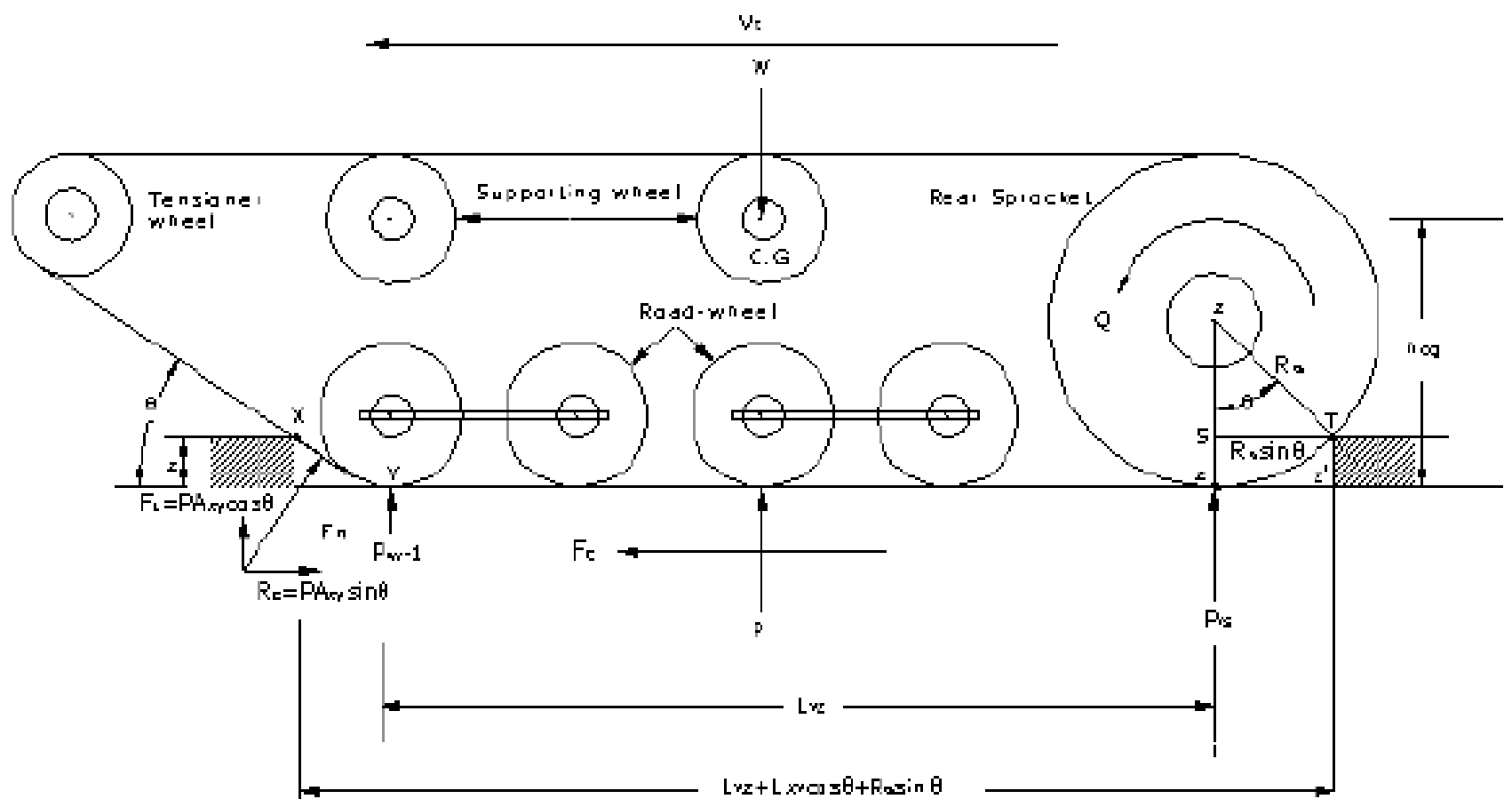

Fig. (2). Force acting on track system. 
cushion-terrain interaction mechanism. However, only the traction equation of the vehicle for the moderated terrain is computed based on the track-terrain interaction mechanism by using the recommended equation of ref. [6]:

For sinkage, $0 \leq z<50 \mathrm{~mm}$

$$
F_{b}=\left(A_{t} c+\left(W_{t}\right) \tan \varphi\right)\left[\frac{K_{w}}{i L} e^{1}-\left(1+\frac{K_{w}}{i L}\right) \exp \left(1-\frac{i L}{K_{w}}\right)\right]
$$

where, $A_{t}=2\left(L_{Y Z}\right)(B)$ and $L=L_{Y Z}$

In Equation (1), $F_{b}$ is the traction that develops at the bottom part of the track in $\mathrm{kN}, L$ is the ground contact part of the track in $\mathrm{m}, A_{t}$ is the area of the track ground contact length in $\mathrm{m}^{2}, W_{t}$ is the vehicle load supported by the track system in $\mathrm{kN}, c$ is the cohesiveness in $\mathrm{kN} / \mathrm{m}^{2}, \varphi$ is the terrain internal friction angle in degree, $K_{w}$ is the shear deformation modulus of the terrain in $\mathrm{m}, i$ is the slippage of the vehicle in percentage, and $B$ is the width of the track in $\mathrm{m}$.

For sinkage, $z \geq 50 \mathrm{~mm}$

The vehicle will start to sink severely when the vehicle is assumed to operate on the swamp peat. In this case, the vehicle load will be partially supported by the air-cushion system. It is assumed that the air-cushion system of the vehicle will be in contact with the terrain when the vehicle sinkage is more than $50 \mathrm{~mm}$ (i.e, $z \geq 50 \mathrm{~mm}$ ). The drag motion resistance develops due to the dragging of the aircushion support system with the terrain, which will significantly affect on the vehicle mobility. Therefore, the additional thrust of the vehicle will be needed to develop, in order to overcome the dragging motion resistance of the vehicle. The traction of the vehicle $F_{t}$ is calculated by using the recommended equation of ref. [7]:

$$
F_{t}=\left(A_{t} c+W_{t} \tan \varphi\right)\left[\begin{array}{l}
\frac{K_{w}}{i L} e^{1}- \\
\left(1+\frac{K_{w}}{i L}\right) \exp \left(1-\frac{i L}{K_{w}}\right)
\end{array}\right]+F_{\text {tac }(\text { add })}
$$

where, $A_{t}=\left(L_{X Y} \cos \theta+L_{Y Z}+R_{r s} \sin \theta\right)(2 B)$,

$$
L=\left(L_{X Y} \cos \theta+L_{Y Z}+R_{r s} \sin \theta\right) \text { and } L_{X Y}=\frac{z}{\sin \theta}
$$

In Equation (2), $F_{\text {tac(add) }}$ is the additional tractive effort developed by the propeller in $\mathrm{kN}$, and $\theta$ is the angle between the track of $1^{\text {st }}$ road-wheel to tensioned wheel and the ground in degree.

Fig. (3) shows the mechanics of the automated adjusted air-cushion protecting system. It is made in such a way that its weight does not affect on the vehicle's ground contact pressure and its vertical and longitudinal displacements don't affect the air-cushion inflation pressure as well. The basic objective of this system is to protect the air-cushion system from the external threat on the ground by adjusting its vertical and longitudinal displacements automatically.

The air-cushion system is attached with the HETAV, only for stopping the vehicle sinkage and increasing the vehicle floatation capacity. It would be incurred for the vehicle, once the vehicle transfers its load to the air-cushion system. Load transferring of the vehicle to the air-cushion system starts when the vehicle gets its sinkage $50 \mathrm{~mm}$ or more. The load transfer of the vehicle to the air-cushion system could be formulated as follows:

$$
W_{v(a c)}=\left(P^{\prime}-P\right)\left(A_{B C}\right)=\left(P_{0}^{\prime}\right)\left(A_{B C}\right)
$$

For sinkage, $z_{a c s}=0.0 \mathrm{~mm}$

$$
\begin{aligned}
& W_{v(a c)}=\left[P^{\prime}-\left(k_{p} z_{a c s}+\frac{4}{D_{h a c}} m_{m} z_{a c s}^{2}\right)\right]\left(A_{B C}\right) \\
& \text { where, } z_{a c s}=\frac{-\left(\frac{k_{p} D_{a c s}}{4 m_{m}}\right) \pm \sqrt{\left.\left(\frac{k_{p} D_{a c s}}{4 m_{m}}\right)^{2}+\frac{D_{a c s}}{m_{m}} P_{0}^{\prime}\right]}}{2} \text { and } \\
& D_{a c s}=\frac{4\left(B_{a c s}\right)\left(L_{B C}\right)}{2\left(L_{B C}+B_{a c s}\right)}
\end{aligned}
$$

For sinkage, $z>50 \mathrm{~mm}$

$$
W_{v(a c)}=\left[P^{\prime}-\left(k_{p} z_{a c s}+\frac{4}{D_{h a c}} m_{m} z_{a c s}^{2}\right)\right]\left(A_{B C}+2 A_{B C^{\prime}}\right)
$$

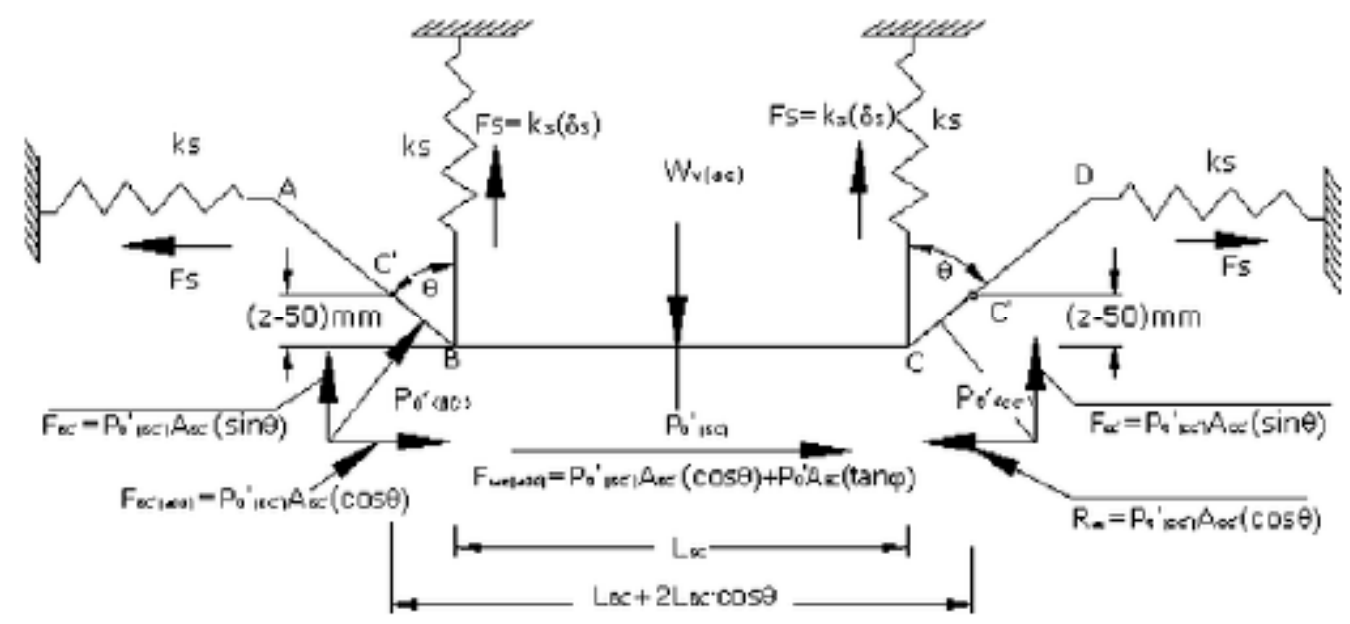

Fig. (3). Air-cushion support system. 


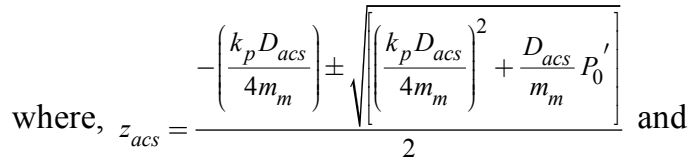
$D_{a c s}=\frac{4\left(B_{a c s}\right)\left(L_{B C}+2 L_{B C} \cos \theta\right)}{\left(L_{B C}+2 L_{B C} \cos \theta+B_{a c s}\right)}$

In Equation (3), $P_{0}{ }^{\prime}$ is the ground nominal pressure which could exist due to the transfer load of the vehicle to the air-cushion system in $\mathrm{kN} / \mathrm{m}^{2}, P$ is the vehicle ground contact pressure in $\mathrm{kN} / \mathrm{m}^{2}$, and $A_{B C}$ is the contact area of the air-cushion support system as shown in Fig. (3). It is noted that the vehicle sinkage will be zero or less than $50 \mathrm{~mm}$ (i.e, $0.0 \mathrm{~mm} \leq z<50 \mathrm{~mm}$ or $P_{0}^{\prime}=0$ ), which indicates that the aircushion will not be in contact with the terrain. In swamp peat terrain, it is absolutely not possible to make the sinkage zero (i.e., $z=0$ ) for any vehicle. While in some instant it could be less than $50 \mathrm{~mm}$. The sinkage of this vehicle will be more than $50 \mathrm{~mm}$, if the vehicle is not equipped with air-cushion. Therefore, the vehicle sinkage will be limited to $50 \mathrm{~mm}$ by using an air-cushion system. The air-cushion system supports the vehicle's partial load and makes the vehicle ground contact pressure less than the ground (terrain) nominal pressure.

In Equations (4) and (5), $z_{a c s}$ is the sinkage of the aircushion-support system in $\mathrm{m}$, and $D_{a c s}$ is the hydraulic diameter with respect to the air-cushion-support system in $\mathrm{m}$.

The additional thrust that was developed by the vehicle at the air-cushion system could be calculated as follows:

For sinkage, $z<50 \mathrm{~mm}$ when the vehicle load is considered $2.45 \mathrm{kN}$.

$$
F_{\text {tac }(\text { add })}=P_{0}^{\prime} A_{B C}(\tan \varphi)
$$

For vehicle sinkage, $z>50 \mathrm{~mm}$ when the vehicle load is considered $3.43 \mathrm{kN}$.

$$
F_{\text {tac }(\text { add })}=P_{0}^{\prime} A_{A B}(\cos \theta)+P_{0}^{\prime} A_{B C}(\tan \varphi)
$$

\section{Motion Resistance}

The motion resistance is due to the rolling resistance of the track system, which is mainly due to the terrain compaction. Furthermore, the external motion resistance of the vehicle will also be incurred due to the dragging of the air-cushion, when the vehicle will sink $50 \mathrm{~mm}$ or more. The motion resistance of the vehicle due to the train compaction:

For sinkage, $z=0.0 \mathrm{~mm}$

$R_{c}=2(P)(B)\left(L_{Y Z}\right)(\tan \varphi)$

where, $P=\left(k_{p} z+\frac{4}{D_{h t}} m_{m} z^{2}\right)$,

$z=\frac{-\left(\frac{k_{p} D_{h t}}{4 m_{m}}\right) \pm \sqrt{\left[\left(\frac{k_{p} D_{h t}}{4 m_{m}}\right)^{2}+\frac{D_{h t}}{m_{m}} p^{\prime}\right]}}{2}$,

$D_{h t}=\frac{4 B L_{Y Z}}{2\left(L_{Y Z}+B\right)}$ and $P^{\prime}=\frac{W}{\left(L_{Y Z}\right)(2 B)}$
For sinkage, $z=50 \mathrm{~mm}$

$$
\begin{aligned}
R_{c}= & (2)(B)\left(L_{Y Z}+L_{X Y} \cos \theta+R_{r s} \sin \theta\right)(P)+ \\
& P_{0}^{\prime} A_{B C}(\tan \varphi)
\end{aligned}
$$

where, $P=P_{0}^{\prime}, P$ is the nominal ground pressure that is considered for tracked system, while $P_{0}{ }^{\prime}$ is for cushion support system. The pressure $P$ could be computed by using the following equation of ref. [8]:

where, $P=\left(k_{p} z+\frac{4}{D_{h t}} m_{m} z^{2}\right)$,

$D_{h t}=\frac{(4)(B)\left(L_{Y Z}+L_{X Y} \cos \theta+R_{r s} \sin \theta\right)}{2\left(L_{Y Z}+L_{X Y} \cos \theta+R_{r s} \sin \theta+B\right)}$ and

$P=\frac{W}{\left(L_{Y Z}+L_{X Y} \cos \theta+R_{r s} \sin \theta\right)(2 B)}$

For vehicle sinkage, $z>50 \mathrm{~mm}$

$R_{c}=(2)(B)\left(L_{Y Z}+L_{X Y} \cos \theta+R_{r s} \sin \varphi\right)(P)+$

$P_{0}^{\prime} A_{C D}(\cos \theta)+P_{0}^{\prime} A_{B C}(\tan \varphi)$

For the sinkage, $z>50 \mathrm{~mm}$, the hydraulic diameter $D_{h}$ of the vehicle for the track system will follow the same equation as stated in Equation (18). Only the $L_{X Y}$ will change due to the change in the position of $X$ on the track, as shown in Fig. (2).

\section{SIMULATION}

Fig. (4) shows the swamp peat terrain in Malaysia. The bearing capacity of swamp peat in Malaysia is considered $5 \mathrm{kN} / \mathrm{m}^{2}$ based on the study of ref. [9] and surface mat thickness $50 \mathrm{~mm}$ have been considered in this study. Authors ref. [8] reported that the surface mat of the peat or muskeg terrain is the traficability of the terrain to allow the vehicle to travel rather than to sink. The swamp peat terrain parameters include: $\omega$ is the moisture content in percentage, $c$ is the cohesiveness in $\mathrm{kN} / \mathrm{m}^{2}, \varphi$ is the internal frictional angle in degree, $K_{w}$ is the shear deformation modulus in $\mathrm{m}, m_{m}$ is the surface mat stiffness in $\mathrm{kN} / \mathrm{m}^{3}$, and $k_{p}$ is the underlying peat

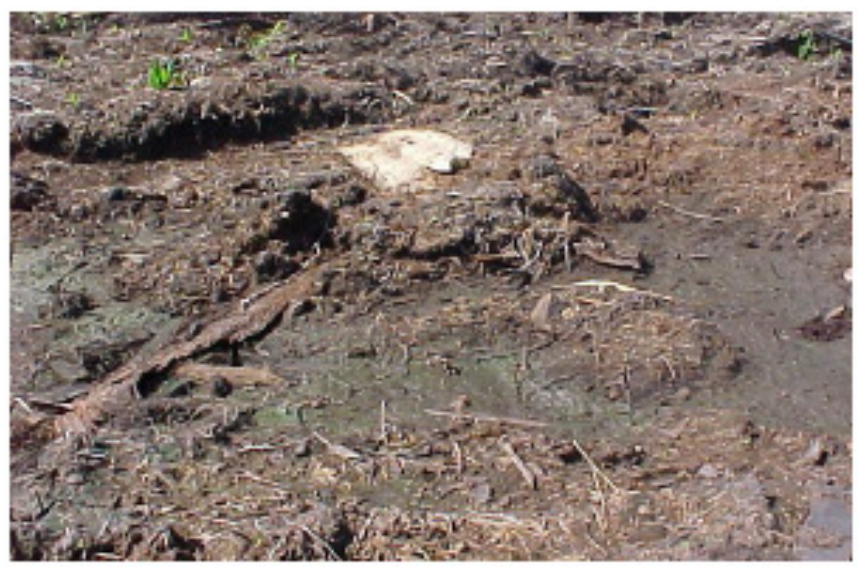

Fig. (4). Photo of swamp peat in Malaysia. 
Table 1. Terrain Parameters

\begin{tabular}{|c|c|c|}
\hline \multirow{2}{*}{ Parameters } & \multicolumn{2}{|c|}{ Un-drained } \\
\cline { 2 - 3 } & Sepang & Marwak \\
\cline { 2 - 3 } & Mean Value & 98 \\
\hline \hline$\omega,(\%)$ & 90.51 & 0.045 \\
\hline$\gamma,\left(\mathrm{g} / \mathrm{cm}^{3}\right)$ & 0.082 & 0.38 \\
\hline$c,\left(\mathrm{kN} / \mathrm{m}^{2}\right)$ & 0.78 & 20 \\
\hline$\varphi$, degree $)$ & 12.64 & 1.24 \\
\hline$K_{w},(\mathrm{~cm})$ & 0.635 & 7.42 \\
\hline$M_{m},\left(\mathrm{kN} / \mathrm{m}^{3}\right)$ & 14.42 & \\
\hline$K_{p},\left(\mathrm{kN} / \mathrm{m}^{3}\right)$ & 119.65 & \\
\hline
\end{tabular}

Source: Ataur et al. (2004).

stiffness in $\mathrm{kN} / \mathrm{m}^{3}$, as shown in Table 1. As the mechanical properties of the swamp peat terrain is very difficult to measure and is not available, in this study the swamp peat terrain is considered $50 \%$ worst than the peat terrain parameters of Sepang based on the study of ref. [10]. The vehicle loading conditions of $2.45 \mathrm{kN}$ and $3.43 \mathrm{kN}$ and the traveling speed of $12 \mathrm{~km} / \mathrm{h}$ are considered for the study of vehicle design parameters. The simulation on the vehicle design parameters and performance are conducted by using the MATLAB.

Fig. (5) shows the relationship between the vehicle tractive effort and motion resistance. Result shows that the vehicle is able to traverse on the terrain, if the vehicle terrain compaction motion resistance remains within the shaded area. In this study, the vehicle with total contact area 1.052 $\mathrm{m}^{2}$ including $0.544 \mathrm{~m}^{2}$ of air-cushion area was optimized based on the bearing capacity of the terrain. Therefore, the track system will only be able to develop $0.75 \mathrm{kN}$, while the additional $0.15 \mathrm{kN}$ tractive effort has needed to develop by the propeller, in order to traverse the vehicle on the peat terrain with overcoming the motion resistance.

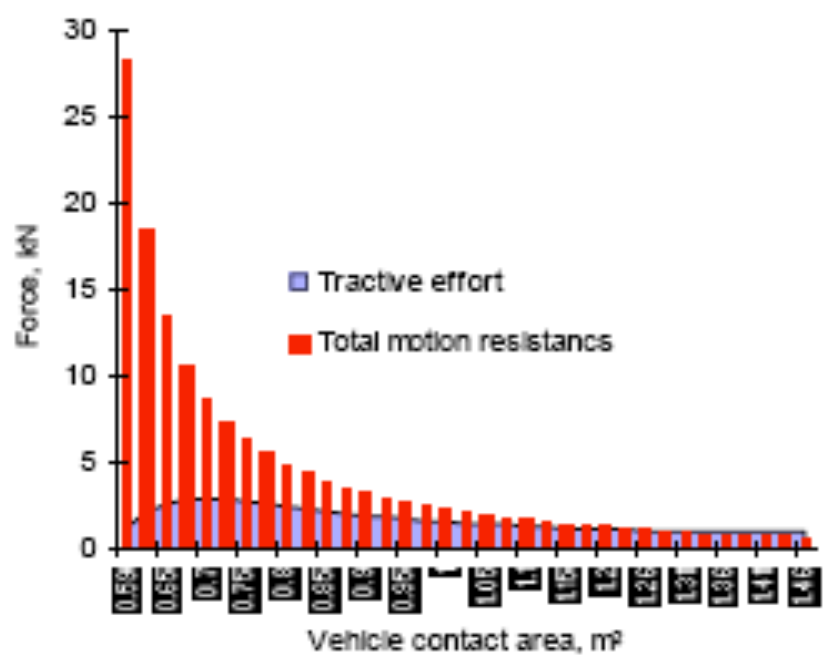

Fig. (5). Relationship between the force and the motion resistance for the vehicle weight $=3.43 \mathrm{kN}$.

Fig. (6) shows the load distribution (defined as the load transferred from the traveling system to air-cushion system in order to limit the vehicle sinkage and to maintain the vehicle ground contact pressure). The load distribution to the air-cushion system is decreased linearly by increasing the track ground contact area. The vehicle with ground contact area of $1.052 \mathrm{~m}^{2}$ has distributed load of $0.45 \mathrm{kN}$ and power consumption by the propeller of $1.02 \mathrm{~kW}$.

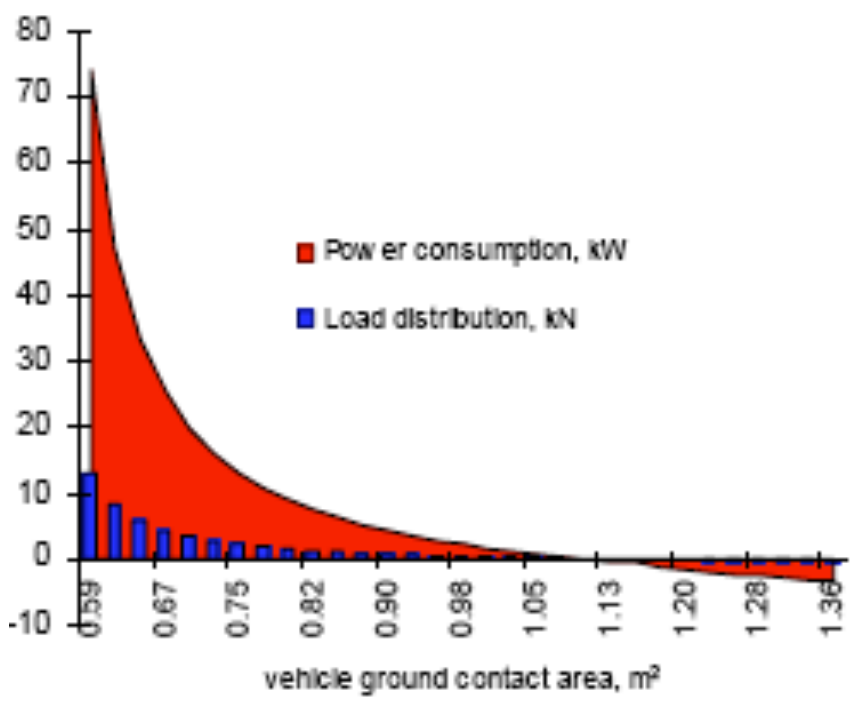

Fig. (6). Relationship of the power consumption and load distribution for the vehicle weight $=3.43 \mathrm{kN}$.

The vehicle optimum ground contact area of $1.052 \mathrm{~m}^{2}$ which included track ground contact area of $(2 \times 1.0 \mathrm{~m} \mathrm{x}$ $0.254 \mathrm{~m}$ ) or $0.508 \mathrm{~m}^{2}$ and air-cushion area of $0.544 \mathrm{~m}^{2}$, the vehicle traveling length of $200 \mathrm{~m}$ over the swamp peat terrain and the vehicle loading conditions of $2.45 \mathrm{kN}$ and $3.43 \mathrm{kN}$ are considered for the simulation of vehicle ground contact pressure, traction, and load distribution. Fig. (7) shows the difference of vehicle ground contact pressure over the ground nominal pressure (GNP). Ground nominal pressure is defined as the pressure that exists from the ground with respect to the static or dynamic vehicle on that ground. While the vehicle ground contact pressure is defined as the pressure that distributes to the ground with the ground contact area of the vehicle. Result showed that the VGPwithout air-cushion is always higher than the ground nominal pressure. It is noted earlier in this study that the 


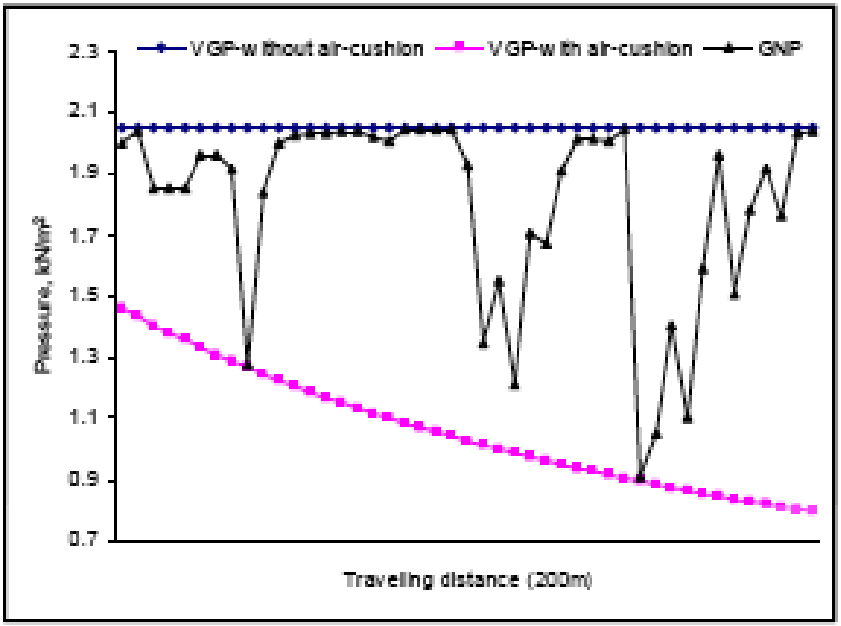

(a) Vehicle weight $=2.45 \mathrm{kN}$

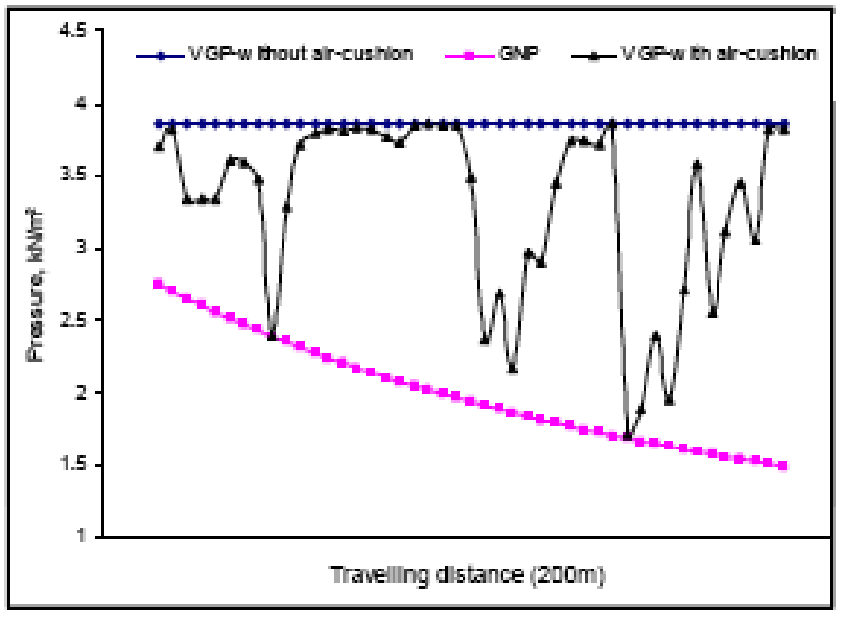

(b) Vehicle weight $=3.43 \mathrm{kN}$

Fig. (7). Variation of the vehicle ground contact pressure (VGP) and ground nominal pressure (GNP).

vehicle will sink, if $P>P_{0}^{\prime}$ and it is also supported by ref. [11]. Therefore, air-cushion system is attached with the vehicle in order to maintain the vehicle sinkage and ground contact pressure. By using the air-cushion system, the VGP is always lower than the GNP. So, the vehicle would be able to travel on the terrain without any risk.

The vehicle was designed in such a way that it would travel on the moderate type of peat terrain with the help of tracked system by overcoming the motion resistance as the tracked total ground contact area was optimized based on the minimum motion resistance exist on the tracked system, bearing capacity of the moderate terrain of $12 \mathrm{kN} / \mathrm{m}^{2}$, and maximum traction developed by the tracked system both in straight and turning motion. In this study, the simulation on the motion resistance and traction was conducted for the vehicle on $200 \mathrm{~m}$ traveling distance swamp peat terrain. Fig. (8) shows that the vehicle would stuck on the terrain if (VT-without air-cushion) $<V R T . V T$ is defined as the vehicle traction (tractive effort) and VRT is defined as the vehicle total motion resistance. But, it would traverse on the terrain if $(V T-$ with air-cushion $)>V R T$. Therefore, it

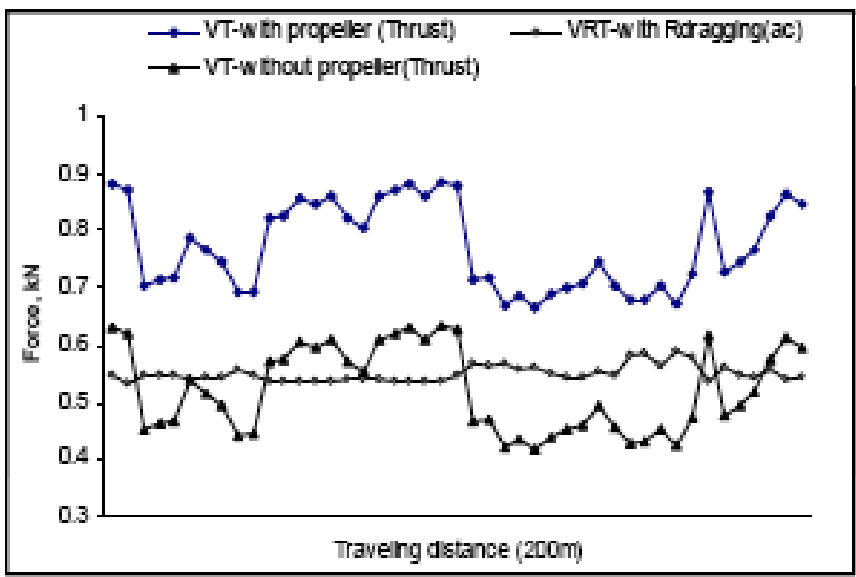

(a) Vehicle weight $=2.45 \mathrm{kN}$ would be concluded that the air-cushion system is a crucial part for the vehicle, which reduce the vehicle motion resistance with reducing the vehicle sinkage. Furthermore, the traction of this vehicle would need to increase in order to overcome the vehicle total motion resistance. So, emphasis has been given to equip a propeller with the vehicle to develop additional thrust.

Fig. (9) shows that the load transfer to the air-cushion system increases with increasing the vehicle loading conditions which significantly affect the power consumption by the vehicle for overcoming the motion resistance. This conclusion is also supported by ref. [12]. Therefore, the loading condition for this vehicle is limited to $3.43 \mathrm{kN}$, as the power of the vehicle battery pack is $3.5 \mathrm{~kW}$.

\section{VEHICLE DEVELOPMENT}

Fig. (10) shows the designed and developed HETAV. Steering of this vehicle was achieved by means of an individual switch of the DC motor with a power of $0.500 \mathrm{~kW} @ 2.94 \mathrm{Nm}$. The dry weight of the vehicle equals to $1.02 \mathrm{kN}$. The vehicle is designed mainly for operating maximum load of $3.43 \mathrm{kN}$, including $1.02 \mathrm{kN}$ payload over

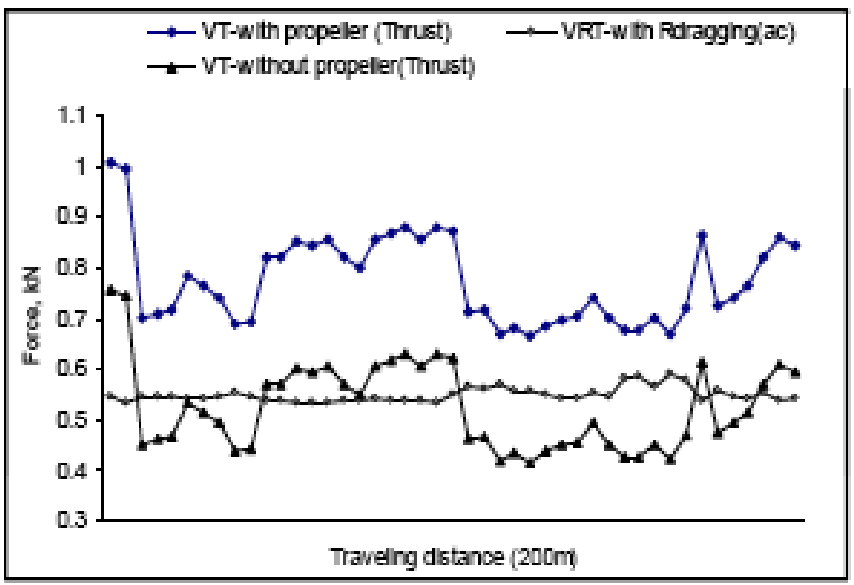

(b) Vehicle weight $=3.43 \mathrm{kN}$

Fig. (8). Variation of the vehicle traction (VT) and vehicle motion resistance (VRT). 


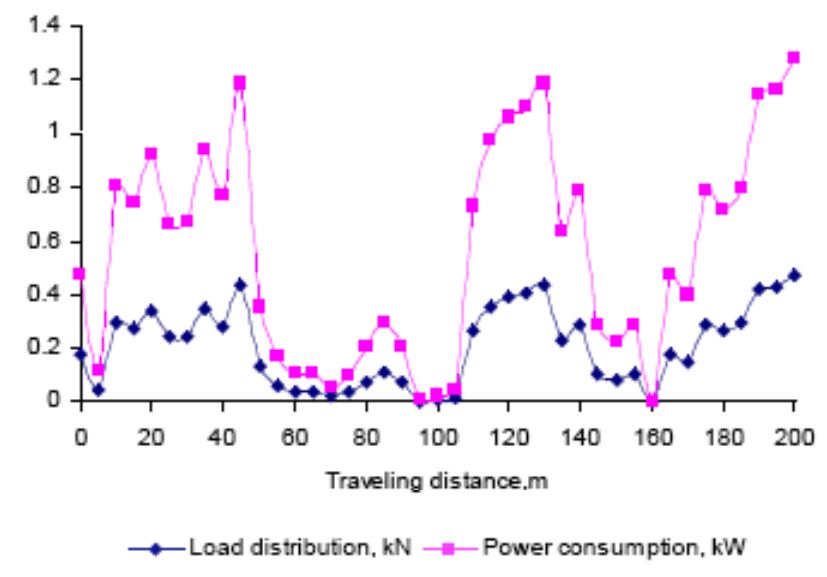

(a) Vehicle weight $=2.45 \mathrm{kN}$

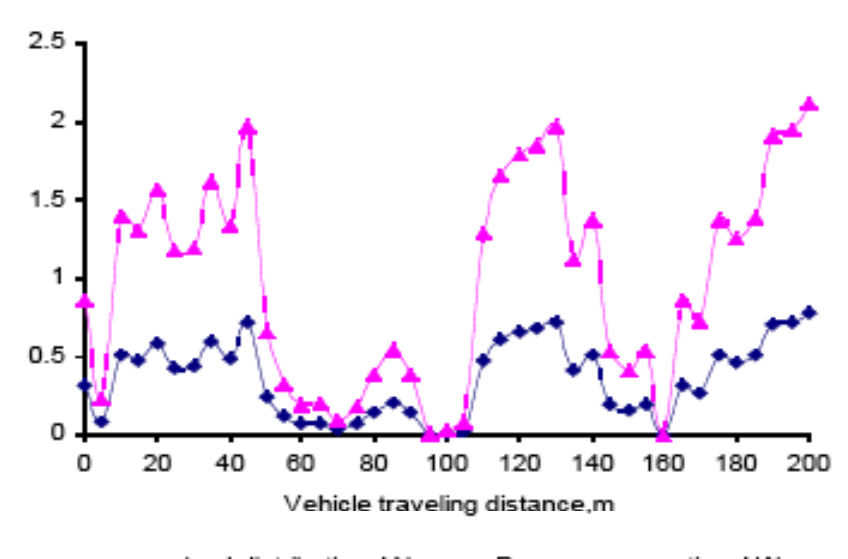

—— load distribution, $\mathrm{kN}$ —_Low er consumption, kW

Vehicle weight $=3.45 \mathrm{kN}$

Fig. (9). Affect of load distribution of air-cushion on the vehicle power consumption.

the swamp peat terrain. The total ground contact area of the vehicle is $1.052 \mathrm{~m}^{2}$, which sum-up the track ground contact area of $(2 \times 1 \mathrm{~m} \mathrm{x} 0.254 \mathrm{~m})$ or $0.508 \mathrm{~m}^{2}$ and the air-cushion contact area of $0.544 \mathrm{~m}^{2}$. The vehicle is powered by a battery pack comprising of four batteries ( 4 × $3 \mathrm{~kg}$ ) of 12 volts, connected in parallel. The vehicle can travel $15 \mathrm{~km}$ by using the power from the single charged battery pack. A small IC Engine power of $2.5 \mathrm{~kW} @ 4000 \mathrm{rpm}$ is installed on the vehicle to recharge the battery pack with the help of an alternator. The vehicle is controlled by a remote control system from the road side in order to avoid the risk, if there is any.

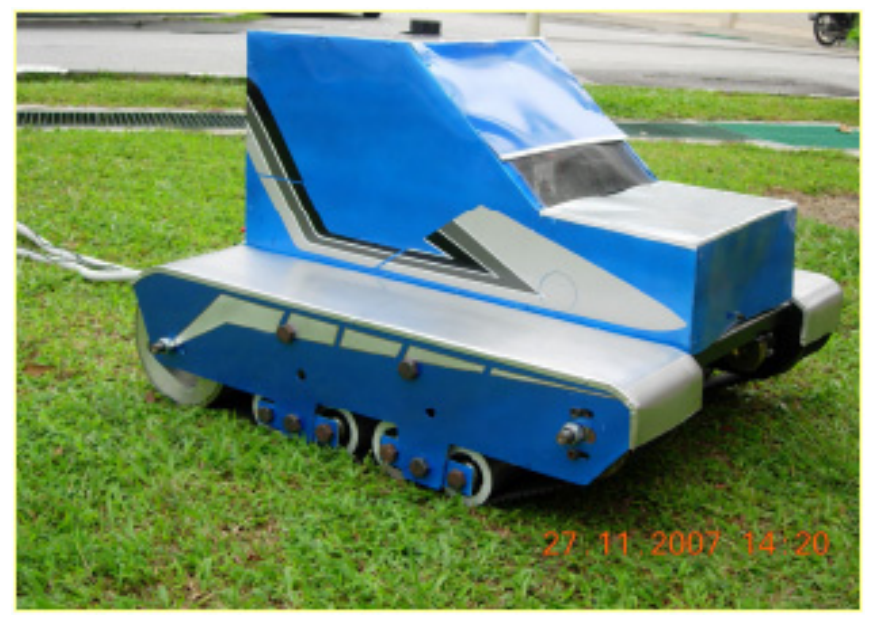

Fig. (10). Photo of the vehicle.

\section{FIELD (LABORATORY) EXPERIMENT}

Vehicle was tested on the swamp peat terrain at a traveling speed of $10 \mathrm{~km} / \mathrm{h}$ and $15 \mathrm{~km} / \mathrm{h}$ with the loading conditions of $2.45 \mathrm{kN}$ and $3.43 \mathrm{kN}$ including the dry weight of $.02 \mathrm{kN}$. The vehicle traveling distance during testing was considered $50 \mathrm{~m}$. During testing it was found that to travel over the swamp peat without payload is not a problem for vehicle, but the vehicle starts to sink when its load increased to $2.45 \mathrm{kN}$ and $3.43 \mathrm{kN}$. Furthermore, the vehicle was tested on the swamp terrain by using the air-cushion system with two conditions: (i) without operating the propeller, and (ii) with operating the propeller. The output torque of the DC motor was measured and was converted into tractive effort. The motion resistance test was performed by pulling the vehicle with an auxiliary vehicle. It was noted that a loaded cell was placed in between the tested and auxiliary vehicle. Data were recorded from the loaded cell in every 5 seconds. Figs. (11-13) show the typical variations of tractive effort and motion resistance of the HETAV. The mean values of vehicle tractive effort and motion resistance are shown in Table 2.
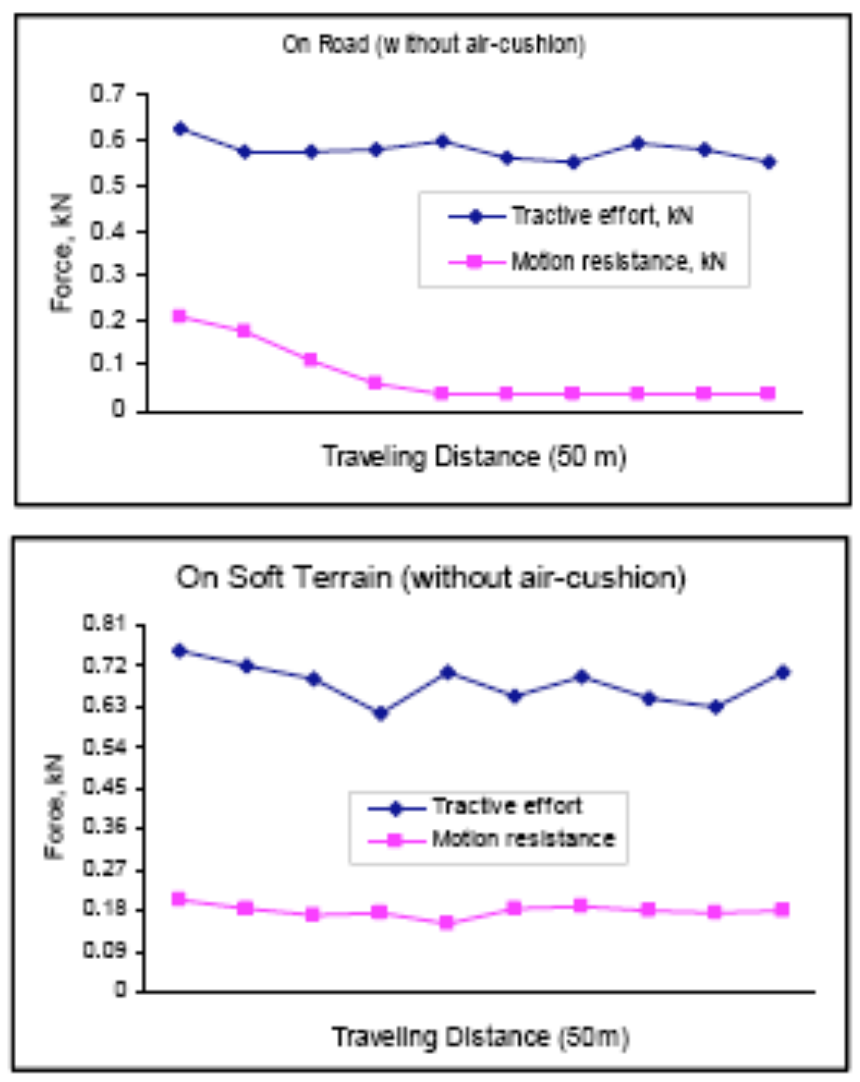

Fig. (11). Variation of tractive effort and motion resistance for the vehicle weight $=2.45 \mathrm{kN}$.

The results show that the mean value of traction for the swamp terrain with the propeller over without propeller increases $10.21 \%$ and $6.47 \%$ for the vehicle weight of 2.45 

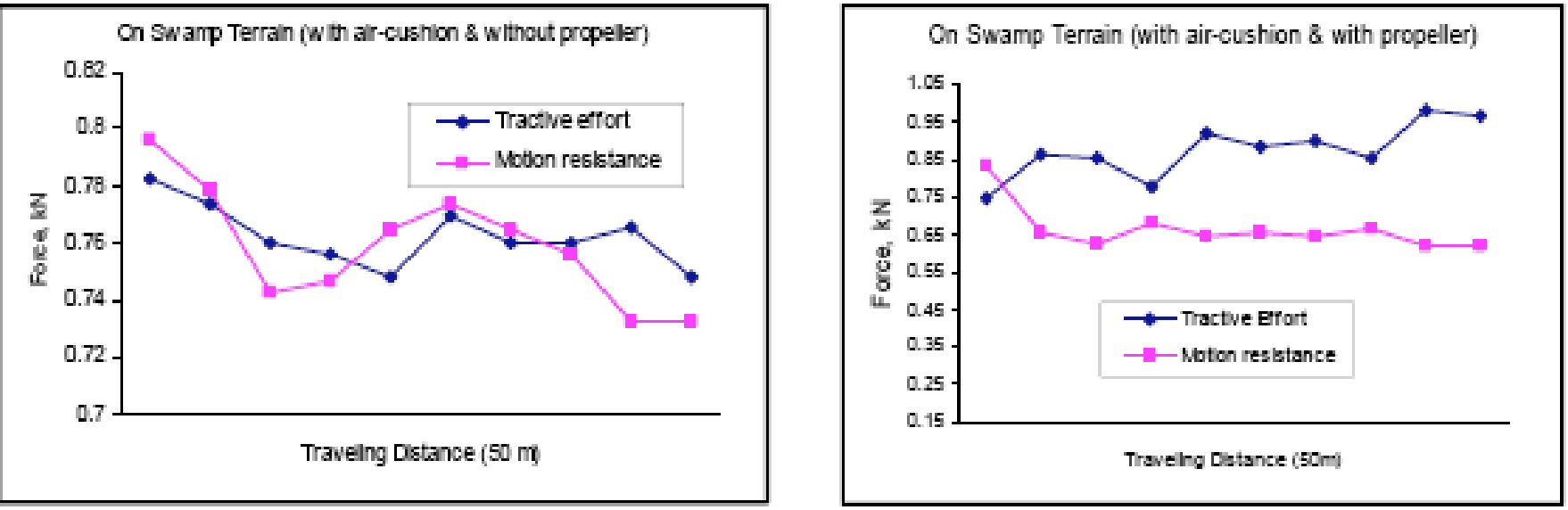

Fig. (12). Variation of tractive effort and motion resistance for the vehicle weight $=2.45 \mathrm{kN}$.
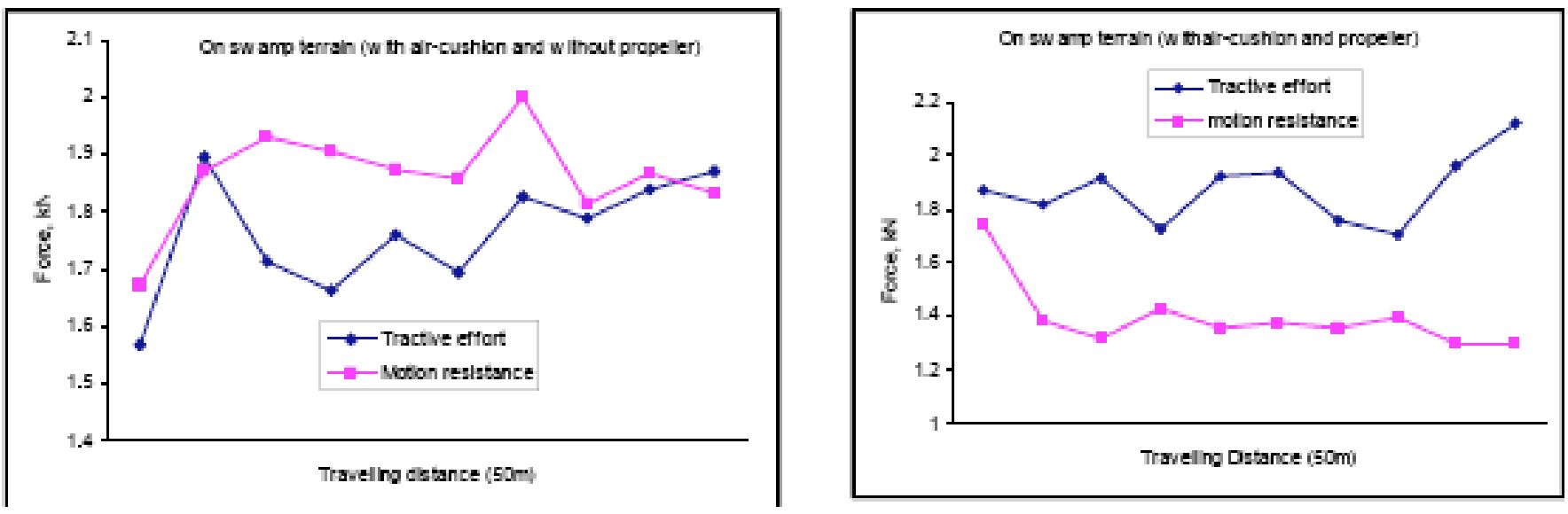

Fig. (13). Variation of tractive effort and motion resistance for the vehicle weight $=3.43 \mathrm{kN}$.

$\mathrm{kN}$ and $3.43 \mathrm{kN}$, respectively. Similarly, it was found that the motion resistance decreases $12.63 \%$ and $24.81 \%$ for the vehicle weight of $2.45 \mathrm{kN}$ and $3.43 \mathrm{kN}$, respectively. It is concluded that the increment and decrement of the tractive effort and motion resistance are due to the additional tractive effort developed by the propeller. Furthermore, the mean value of tractive effort increases swamp terrain mainly due to the increment of loading conditions of the vehicle as the cohesiveness of the field is approximately constant for all the traveling length. The conclusion is also supported by the conclusion remarks of ref. [8], ref. [10], and ref. [11].

\section{CONCLUSIONS}

The conclusions that are made based on the discussion of this study are as follows:

1. The air cushion was activated as soon as the vehicle sinkage was closed to $0.05 \mathrm{~m}$.

2. Based on the simulation result, the following conclusions could be made:

(i) The vehicle load distribution to the air-cushion system would not be too much, since the power consumption by the air-cushion drag motion resistance is too high

Table 2. Mean Values of Tractive Effort and Motion Resistance

\begin{tabular}{|c|c|c|c|c|c|c|c|}
\hline \multicolumn{4}{|c|}{ Tractive Effort (kN) } & \multicolumn{4}{|c|}{ Motion Resistance (kN) } \\
\hline \multicolumn{8}{|c|}{ Vehicle Weight $=1.02 \mathrm{kN}$} \\
\hline \multirow{2}{*}{ Road } & \multirow{2}{*}{ Soft-terrain } & \multicolumn{2}{|c|}{$\begin{array}{l}\text { Swamp-terrain (equipped with air- } \\
\text { cushion) }\end{array}$} & \multirow{2}{*}{ Road } & \multirow{2}{*}{ Soft-terrain } & \multicolumn{2}{|c|}{$\begin{array}{c}\text { Swamp-terrain (equipped with } \\
\text { air-cushion) }\end{array}$} \\
\hline & & $\begin{array}{l}\text { Without } \\
\text { Propeller }\end{array}$ & $\begin{array}{l}\text { Without } \\
\text { Propeller }\end{array}$ & & & $\begin{array}{l}\text { Without } \\
\text { Propeller }\end{array}$ & $\begin{array}{l}\text { Without } \\
\text { Propeller }\end{array}$ \\
\hline 0.976 & 1.86 & 1.76 & 1.874 & 0.201 & 0.3625 & 1.862 & 1.4 \\
\hline
\end{tabular}


which is also supported by the author ref. [3]. Other than that, the power of the battery pack is too limited.

(ii) The vehicle must have needed to develop an additional thrust of at least $0.2 \mathrm{kN}$, as the vehicle track ground contact area is optimized by $0.505 \mathrm{~m}^{2}$.

(iii) Air-cushion system of the vehicle makes the vehicle ground contact pressure less than $5 \mathrm{kN} / \mathrm{m}^{2}$, with partially supporting the vehicle load.

(iv) The propellers must have to manage an additional thrust of $0.20 \mathrm{kN}$, while the track system developed only $0.665 \mathrm{kN}$ and $1.674 \mathrm{kN}$.

3. The battery pack provided the power to the DC motor only for a $15 \mathrm{~km}$ traveling distance, which was found based on the depth-of-discharge of the battery.

4. Based on the laboratory experimental results, the following conclusion could be made:

(i) According to the mean values of vehicle tractive performance in terms of tractive effort and motion resistance, the vehicle would not be able to traverse on the swamp terrain with air-cushion and the additional thrust of the propeller.

(ii) The mean value of the tractive effort of the vehicle increases by increasing the vehicle loading conditions and it could be due to the changing of the track ground contact area. Since the track width is constant and the track ground contact length increases with increasing the sinkage. So that the track ground area is the function of the track ground contact length i.e $A=\oint(L, W)$

where, $\quad L=L_{Y Z}$ or $L_{Y Z}(1+\cos \theta)+R_{R S} \sin \theta \quad$ and vehicle load as well.

(iii) Traction coefficient of the vehicle in the range of 77$85 \%$ make the vehicle highly potential to operate on the swamp peat terrain.

(iv) The vehicle sinkage is not possible to limit at $50 \mathrm{~mm}$, if the vehicle is not equipped with air-cushion system. Furthermore, the vehicle will stuck on the swamp terrain, if the vehicle is equipped with air-cushion and the dragging motion resistance of the air-cushion system is considerably high. Therefore, the vehicle must have to equip with air-cushion system and propeller in order to operate on the swamp terrain without any difficulties.

(v) The novel-design-air-cushion supporting system will make the vehicle more vulnerable to operate on the real swamp peat, as it allows the vehicle to traverse on any unprepared terrain with adjusting the air-cushion automatically by absorbing the longitudinal and vertical displacement.

5. Based on the operating performance of this small-scale vehicle, it could be justified that by introducing the same concept, a full-scale vehicle could be introduced in the swamp peat terrain which would be highly potential for the transportation operation of agricultural goods and others industrial products.

\section{REFERENCE}

[1] H. S. Ooi, "Theoretical investigation on the tractive performance of MALTRAK on soft padi soil," MARDI, Report no.116, 1993.

[2] H. S. Ooi, "Design and development of peat prototype track type tractor", MARDI, Report no. 184, 1996.

[3] A. Shuib, and A. Hitam, "Wakfoot the FFB evacuation vehicle. PORIM Information Series. Palm Oil Research Institute of Malaysia,” PORIM TT No. 20, Pamphlet, 1998.

[4] A. Yahya, M. S. Jaafar, and K. Aribi, "Mechanical infield collection of oil palm fresh fruit bunches," Fruit, Nut, and vegetable production engineering, Vol. 1, pp. 317-326, 1997.

[5] R. Ataur, Y. Azmi, M. Zohadie, D. Ahmad, and W. Ishak, "Design and development of a segmented rubber tracked vehicle for Sepang peat terrain in Malaysia," International Jounal of Heavy Vehicle Systems, Inderscience. Vol. 12, No. 3, pp. 239-267, 2005.

[6] R. Ataur, Y. Azmi, and A. K. M. Mohiuddin, "Mobility investigation of a designed and developed segmented rubber track vehicle for sepang peat terrain in Malaysia," Journal of Automobile Engineering, Proceedings of the IMech E Part D, Vol. 221 (D7) pp. 789-800.

[7] Z. Luo, F. Yu, and B.C. Chen, "Design of a novel semi-tracked aircushion vehicle for soft terrain", International Journal of Vehicle Design, Vol. 31, No. 1, pp. 112-123, 2003.

[8] J. Y. J. Wong, R. Radforth, and J. Preston-Thomas, "Some further studies on the mechanical properties of muskeg in relation to vehicle mobility," Journal of Terramechanics, Vol. 19, No. 2, pp. 107-127, 1982

[9] B. J. Jamaluddin, 2002, "Sarawak peat agricultural uses," [online]. Available: http://www.Alterra.dlo.nl/ [Accessed Feb 2005].

[10] R. Ataur, Y. Azmi, B. Zohaide, D. Ahmad, and I. Wan, "Mechanical properties in relation to mobility of Sepang peat terrain in Malaysia," Journal of Terramechanics, Vol .41, No. 1, pp. 25-40, 2004.

[11] A. Bodin, "Development of a tracked vehicle to study the influence of vehicle parameters on tractive performance in soft terrain," Journal of Terramechanics, Vol. 36, pp.167-181, 1999.

[12] I. C. MacFarlane, Muskeg Engineering Handbook, Toronto, University of Toronto Press, 1969.

This is an open access article licensed under the terms of the Creative Commons Attribution Non-Commercial License (http: //creativecommons.org/licenses/by$\mathrm{nc} / 3.0 /$ ), which permits unrestricted, non-commercial use, distribution and reproduction in any medium, provided the work is properly cited. 